\title{
Numerical study of the effect of geometry variation on the performance of innovative design wind speed enhancer
}

\author{
Theodorus T. Wibowo' ${ }^{1}$ Faizal H. Daulay, Kutut Suryopratomo, and Rachmawan Budiarto \\ ${ }^{1}$ Department of Nuclear Engineering and Engineering Physics, Universitas Gadjah Mada, Yogyakarta, Indonesia
}

\begin{abstract}
Low wind speeds is one of the challenges of wind energy in several countries. The innovative design of wind speed enhancer is one of many solution of those challenges. The wind speed enhancer using the principle of constriction where the speed will be increased at a narrower area. The innovative design wind speed enhancer is unique because of the wind turbines are installed close to the ground surface. The uniqueness can reduce the cost of installation, maintenance, and can reduce the possibility of damage caused by lightning. The proposed of wind speed enhancer design was shown to be successful in increasing the wind speed at venturi that reach 2.26 faster than wind speed at environment for variation of the funnel gap and 2.35 faster than wind speed at environment for variation of the throat diameter. This result is better than existing design. The results of this study is $21.5 \%$ better than existing design for variation of funnel gap and $24.2 \%$ better than existing design for variation of the throat diameter.
\end{abstract}

\section{Introduction}

\subsection{Background}

In this electronic era, the electricity needs of the people of Indonesia is increasing, but there are still people who have not been reached by electric energy. In 2015 Indonesian government made a program called 35,000 MW. In that program, there is a use of fossil energy, and renewable energy.

Fossil fuels are all forms of energy derived from fossil both animals and plants. Fossil fuels have a long life cycle thus classified as non-renewable energy. Some examples of fossil fuels such as coal, oil and natural gas reserves are diminishing every year.

Renewable energy is the energy source that has a short life cycle. There are several examples of renewable energy such as solar energy (solar panels), wind energy (wind turbines), hydro energy, geothermal, and biomass. Renewable energy is one solution to meet energy needs in Indonesia. This article will discuss the solution of problems in the field of wind energy. The biggest problem of wind energy in Indonesia, almost all regions in Indonesia have low wind speed [12].

Wind speed in Indonesia is relatively low while wind turbines available on the market have the specifications for the high speed of wind [8], so it is necessary to increase the speed of the wind to harvest wind energy in Indonesia. By using the venturi principle, wind can be accelerated in a section where the wind turbines will be placed. The wind turbine will be placed close to the ground as it eases the
75 process of installation, maintenance and to avoid damage due to lightning. A similar process has been performed by SheerWind with a project named INVELOX Wind Turbine in 2012-2014 [1-3]. In this research will be carried out numerical studies on several variations of geometry, namely: The variation of ratio between throat's diameter and the diameter of inlet venturi, and the variation of ratio between the gap of funnel and the length of funnel at Innovative design of wind speed enhancers. Numerical studies are conducted using ANSYS and outcomes to be achieved in this research is to obtain optimal geometry variations that increase the highest wind speed.

\subsection{Literature}

Many studies has been done to increase the capacity of wind turbines. Research conducted by Daryoush Allaei, and Yiannis Andreopoulos [1] is one of the research on wind energy issues. The research is to make the design of a device for increasing the speed of the wind, the device is called INVELOX. The device offers a concept to overcome the problem of wind energy in the regions with low wind speeds. 


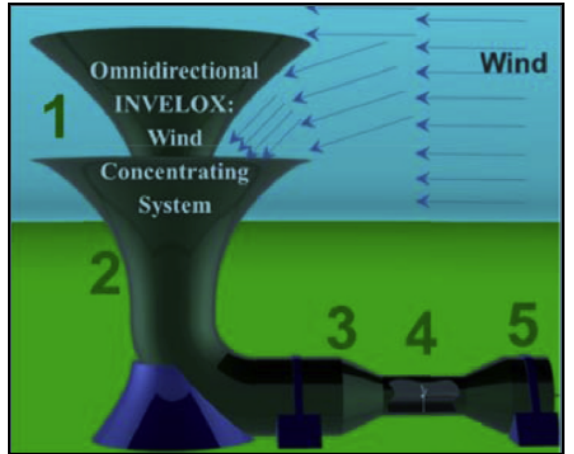

Fig. 1. Schematic INVELOX

INVELOX work scheme consists of 5 sections as shown in Figure 1. The first part is captured the wind from any direction via omnidirectional intake, then collected through a tunnel, after which the the wind is directed through the elbow to the venturi. The wind is accelerated on venturi and the wind turns the turbine so that electricity can be generated. The wind that had been through the wind turbines will be returned to the environment.

In the study conducted two methods: the method of CFD (Computational Fluid Dynamics) and experimental methods. CFD methods that have been carried out using the software ANSYS FLUENT and COMSOL Multiphysics, while the experimental method is done by taking data in the field in Chaska, Minnesota in 2012 and 2013.

Table 1. Data from CFD method

\begin{tabular}{|c|c|c|c|c|c|c|}
\hline \multirow[t]{2}{*}{ Model } & \multirow[t]{2}{*}{ Mesh size } & \multirow{2}{*}{$\begin{array}{l}\text { Free stream } \\
{[\mathrm{m} / \mathrm{s}]}\end{array}$} & \multicolumn{2}{|c|}{ Venturi velocity $[\mathrm{m} / \mathrm{s}]$} & \multicolumn{2}{|c|}{ Speed ratio (SR) } \\
\hline & & & Average & Max & Average & Max \\
\hline ANSYS & Fine & 6.71 & 10.6 & 12.1 & 1.58 & 1.80 \\
\hline \multirow[t]{2}{*}{ COMSOL } & Normal & 6.71 & 10.6 & 12.1 & 1.58 & 1.80 \\
\hline & Fine & 6.71 & 11.7 & 13.1 & 1.74 & 1.95 \\
\hline
\end{tabular}

The experiment on CFD method using ANSYS and COMSOL resulted wind speed ratio reached 1.58 using ANSYS, and reached 1.74 in mesh size: fine using COMSOL.

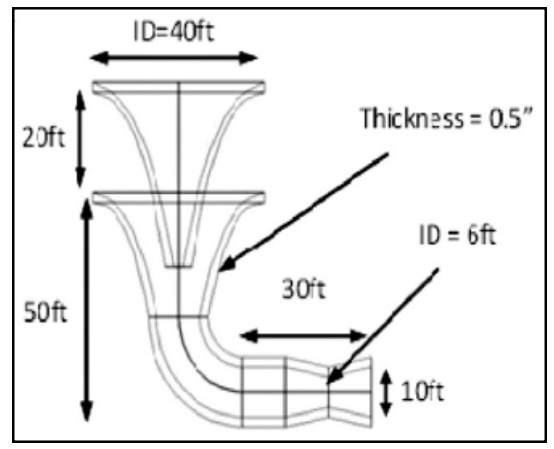

Fig. 2. INVELOX dimension

Figure 2 is a design experiment in Chaska, Minnesota. The results of this experimental method is a graphic of serial data displaying free stream wind, the wind speed at the venturi, and the speed ratio.

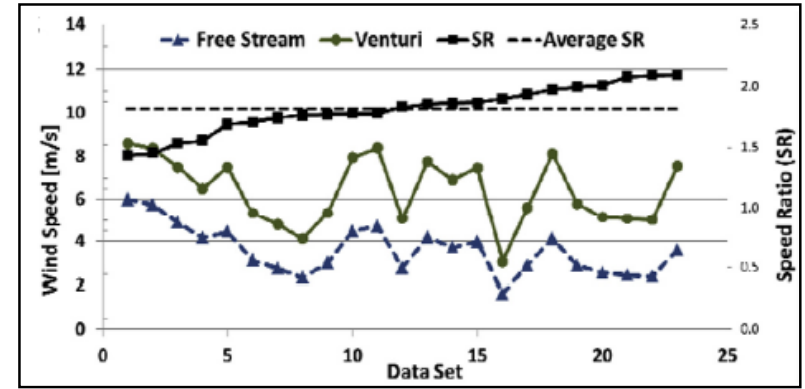

Fig. 3. Data from experiment method

Figure 3 was an experiment result by Daryoush Allei, and Yiannis Andreopoulos [1]. Based on research using CFD and experiment, INVELOX can increase the wind speed reaches the speed ratio 2 . In the present study will use the base geometry similar to the geometry INVELOX and do variations on the intake funnel and a venturi section to improve performance enhancers wind speed

\section{Research Methodology}

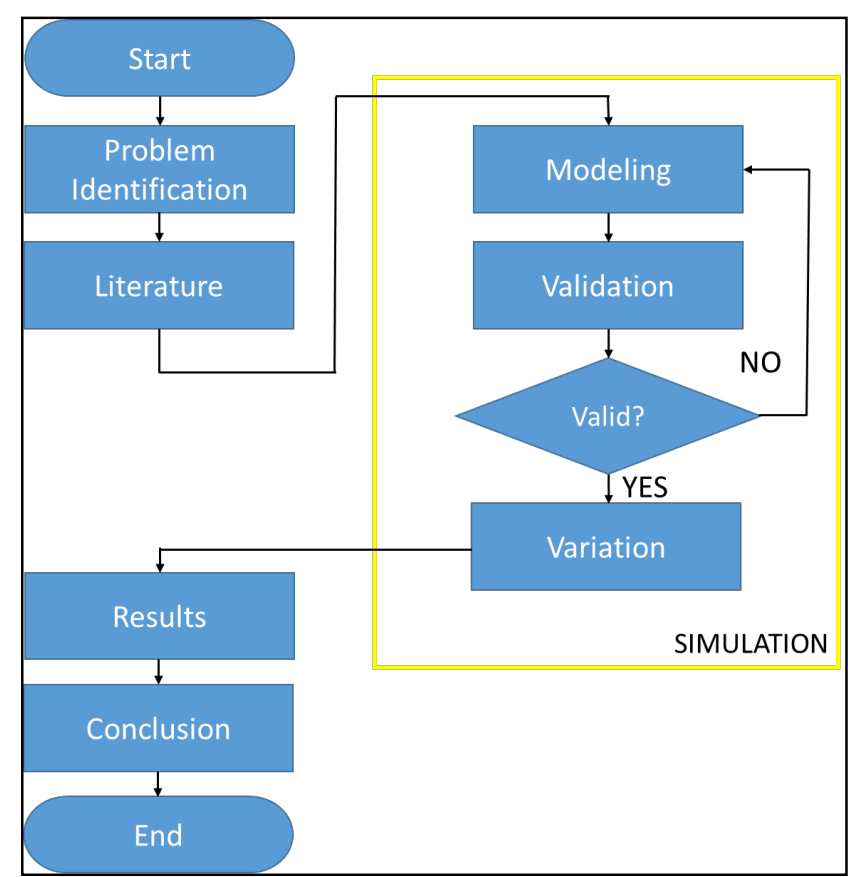

Fig. 4. Flow of research

Data used in this research is secondary data obtained from Daryoush Allaei and Yiannis Adreopoulos on paper "INVELOX: Description of a new concept in wind power and its performance evaluation". Then, the tools used in this research are shown in Table 2. 
Table 2. Research Tools

\begin{tabular}{|r|l|l|}
\hline No. & \multicolumn{1}{|c|}{ Tools } & \multicolumn{1}{|c|}{ Function } \\
\hline 1. & ASUS A455L, processor Intel@ Core & Hardware for simulation \\
& $4210 \mathrm{C}$ CPU @2.4 GHz, Installed memory \\
(RAM) 4.00 GB, 64-bit operating system & \\
\hline 2. & ANSYS 16.2 & Software for design simulation \\
\hline
\end{tabular}

This study uses ANSYS software to perform numerical studies.

\subsection{Modeling}

Modeling is a process that is done in the research using an approach that is expected to resemble the real conditions in the field, the modeling will be done using Ansys.

\subsubsection{Geometry and Boundary Conditions}

The geometry of the wind speed enhancer has the same dimensions with the geometry INVELOX installed in Minnesota. Dimensions of geometry INVELOX contained in Figure 2 in Chapter I. besides geometry wind speed enhancer, virtual wind tunnel also needs to be made. This virtual wind tunnel created as the air domain. The geometry of the wind speed enhancer and virtual wind tunnel shown in the Figure 5.

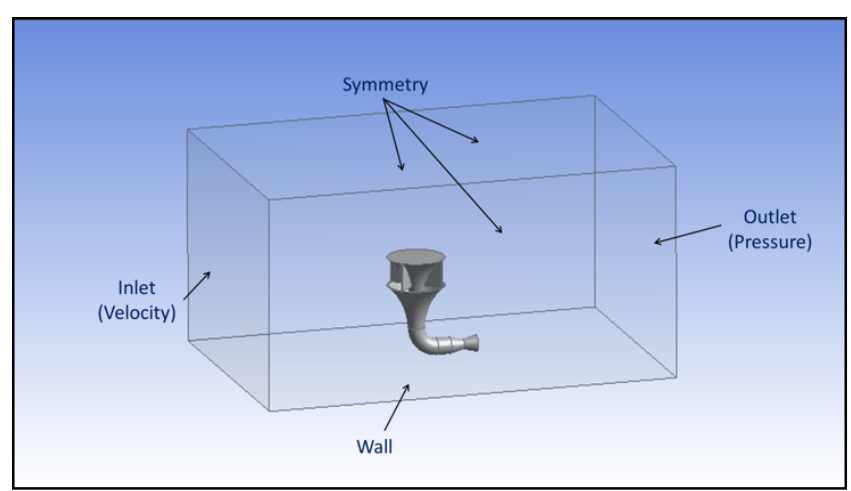

Fig. 5. Geometry and boundary condition

Virtual wind tunnel shaped like a beam with a length of $91.44 \mathrm{~m}$ (300 feet), width of $60.96 \mathrm{~m}$ (200 feet), and 45.72 $\mathrm{m}$ high (150 feet). Type of boundary conditions at the inlet is velocity and the outlet is the pressure. Turbulent Specifications methode at the inlet and outlet is intensity and length scale, turbulent intensity with a value of $5 \%$ and turbulent length scale of $1 \mathrm{~m}$ [1]. The vertical and the top side side of the beam set as wall with a slip condition and the bottom side of the beam set as wall with a no-slip condition because this side indicates the condition of the ground surface.

\subsubsection{Numerical Settings}

Numerical settings used for validation are as follows:

- Solver used in this study is the Pressure-based, with the segregated solver algorithms. Pressurebased solver is excellent in resolving cases at lower Mach number, and requires less memory [13].
- Model used in this study is the k-epsilon turbulence standard wall function.

\subsubsection{Meshing}

Meshing method used is tetrahedral meshing. Mesh is made finer at the venturi as the venturi section is an area of increasing wind speed, so it has a fairly high gradient. After meshing geometry shown in Figure 6.

Fig. 6. Meshing on wind speed enhancher

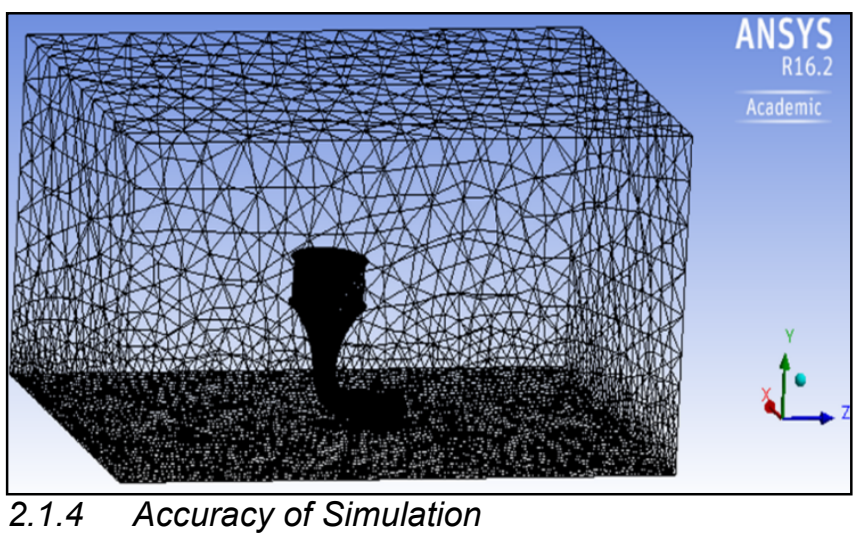

The accuracy of the simulation results in this study were divided into 3 parts: quality mesh, numerical convergence, and mass imbalance.

\section{1) Mesh Quality}

The accuracy of the simulation results in this study were divided into 3 parts: quality mesh, numerical convergence, and mass imbalance.

\begin{tabular}{|c|c|c|c|}
\hline \multicolumn{2}{|l|}{ Statistics } & \multicolumn{2}{|l|}{ Statistics } \\
\hline$\square$ Nodes & 35296 & $\square$ Nodes & 35296 \\
\hline$\square$ Elements & 173875 & $\square$ Elements & 173875 \\
\hline Mesh Metric & Skewness & Mesh Metric & Orthogonal Quality \\
\hline$\square$ Min & $4.9559 \mathrm{e}-005$ & $\square$ Min & 0.12958 \\
\hline$\square$ Max & 0.96955 & $\square$ Max & 0.99541 \\
\hline$\square$ Average & 0.24235 & $\square$ Average & 0.85002 \\
\hline Standard Deviation & 0.13001 & $\square$ Standard Deviation & $9.1547 \mathrm{e}-002$ \\
\hline
\end{tabular}

Fig. 7. Mesh metric quality: Skewness (left), Orthogonal (right)

In Figure 7, the average value of mesh skewness is 0.24 and the average value of orthogonal mesh quality is 0.85 . Mesh can be good or not by comparing these values with the values shown in Figure 8.

\begin{tabular}{|c|c|c|c|c|c|}
\hline \multicolumn{7}{|c|}{ Skewness mesh metrics spectrum } \\
\hline Excellent & Very good & Good & Acceptable & Bad & Unacceptable \\
\hline $0-0.25$ & $0.25-0.50$ & $0.50-0.80$ & $0.80-0.94$ & $0.95-0.97$ & $0.98-1.00$ \\
Orthogonal Quality mesh metrics spectrum & & & \\
\hline \multicolumn{7}{|c|}{} \\
\hline Unacceptable & Bad & Acceptable & Good & Very good & Excellent \\
\hline $0-0.001$ & $0.001-0.14$ & $0.15-0.20$ & $0.20-0.69$ & $0.70-0.95$ & $0.95-1.00$ \\
\hline
\end{tabular}

Fig. 8. Parameter of mesh quality [14].

From Figure 8, it can be seen that the quality of mesh this time are in the excellent category for skewness and very good for the orthogonal quality. 


\section{2) Numerical Convergence}

Convergent numerically can be seen from the plot where the residual convergent condition is reached when the residual graph is straight or showed no decrease in error. In Figure 9, Convergent reached at iteration to 1000, but to ensure the error does not go down again, iterations performed until iteration 2500 .

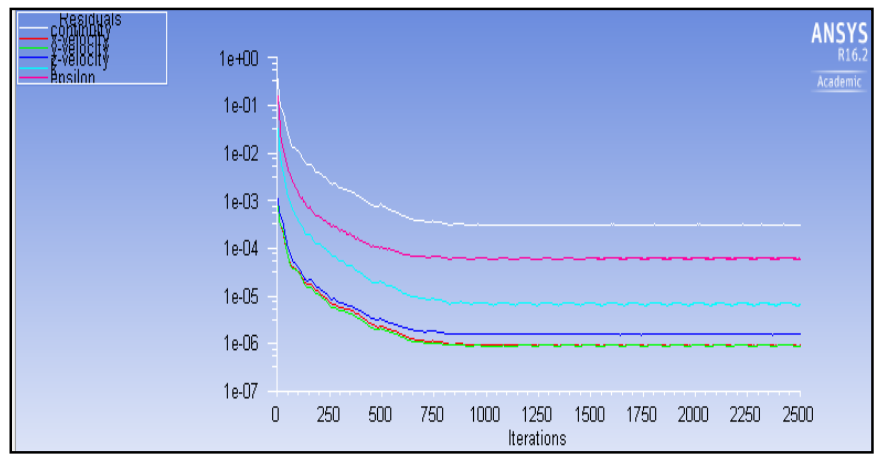

Fig. 9. Scaled residual graphic

\section{3) Mass Imbalance}

Mass balance can be demonstrated using the features of the report fluxes. Inlet and outlet is selected, then select compute as in Figure 10.

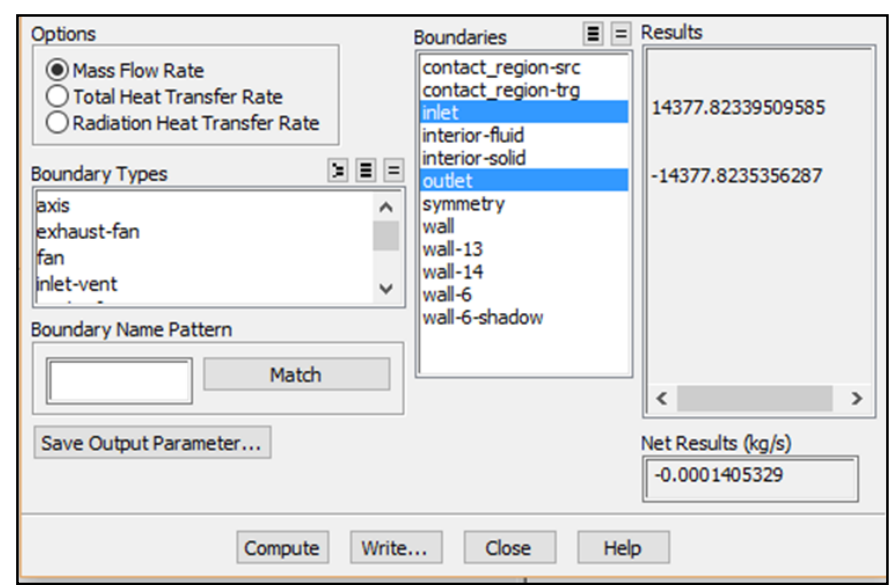

Fig. 10. Flux reports

Mass balance must be met in order to obtain satisfactory results, as shown by the error-value below $1 \%$ [13]. From figure 5.6, the value of net results is $0.0001 \mathrm{~kg}$ / $\mathrm{s}$. This value is derived from the difference between the rate of mass in the inlet and outlet. The value of the net result shows the error is far below $1 \%$ and the mass balance is met.

\subsection{Validation}

This stage is the process of proving whether the simulation results using k-epsilon turbulence models have a value close to the experimental data. The experimental data are secondary data refers to the paper, INVELOX: Description of a new concept in wind power and its performance evaluation by Daryoush Allaei and Yiannis Adreopoulos.
Fig. 11. Validation of modeling with data experiment

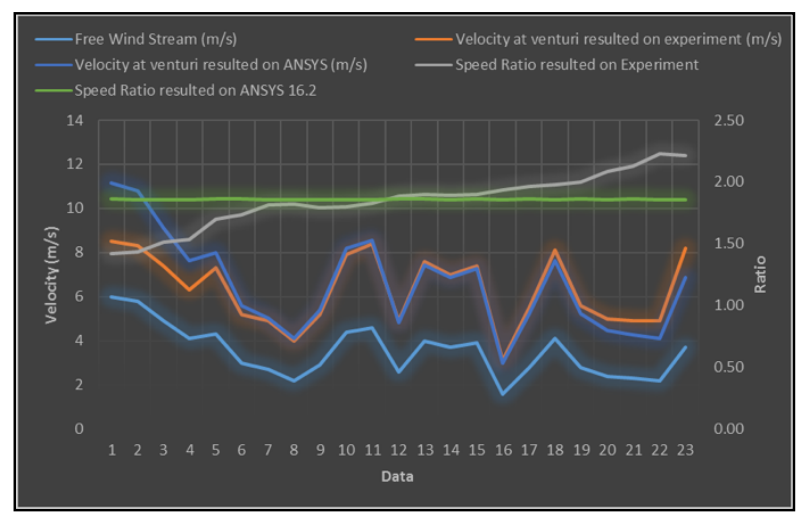

From Figure 11, the wind speed at the venturi from experimental data (orange line) and the data of simulation (dark blue line) shows the same pattern. wind speed ratio of the experiment (gray line) tends to rise while the simulation results (green line) is relatively constant. The difference between the data of simulation and experimental data is expected due to problem definition. Simulations carried out by the direction of the wind has not changed (one way) while the direction of the wind coming in the field can change. The difference from the simulation data and experimental data is not so significant that the model used is said to be valid. After validation, the next is to vary the geometry using models that have been valid.

\subsection{Geometry Variation}

\subsubsection{Variation of the Funnel Gap}

There are two variables that will be the reference to the variation of the length of funnel shown in Figure 12, namely:

- $\quad X=$ the length of the lower funnel.

- $\quad Y=$ the distance between the lower end of the lower funnel to the lower end of the upper funnel.

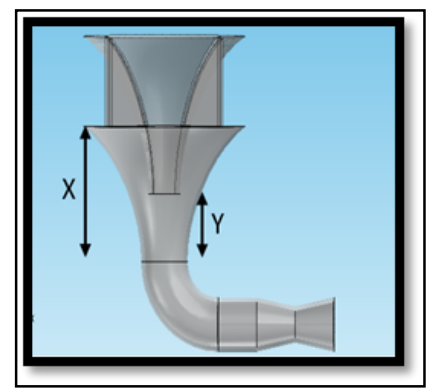

Fig. 12. Funnel gap variation

The length of the lower funnel maintained at 30 feet, according to the problem definition. In this study, free stream velocity, and the distance between the lower end of the lower funnel to the lower end of the upper funnel will be varied as in the following description.

$$
\begin{aligned}
& \mathrm{X}=30 \text { feet } \\
& \mathrm{Y}=0 \text { feet, } 7,5 \text { feet, } 15 \text { feet, } 22,5 \text { feet, } 30 \text { feet }
\end{aligned}
$$




$$
F W S=4 \mathrm{~m} / \mathrm{s}, 3 \mathrm{~m} / \mathrm{s}, 2 \mathrm{~m} / \mathrm{s}, 1 \mathrm{~m} / \mathrm{s}
$$

Variation of geometry is simply the ratio of $\mathrm{y}$ to $\mathrm{x}(\mathrm{y} / \mathrm{x})$ where the ratio of the length of funnel is $0,0.25,0.50$, 0.75, and 1 can be seen in Figure 13.
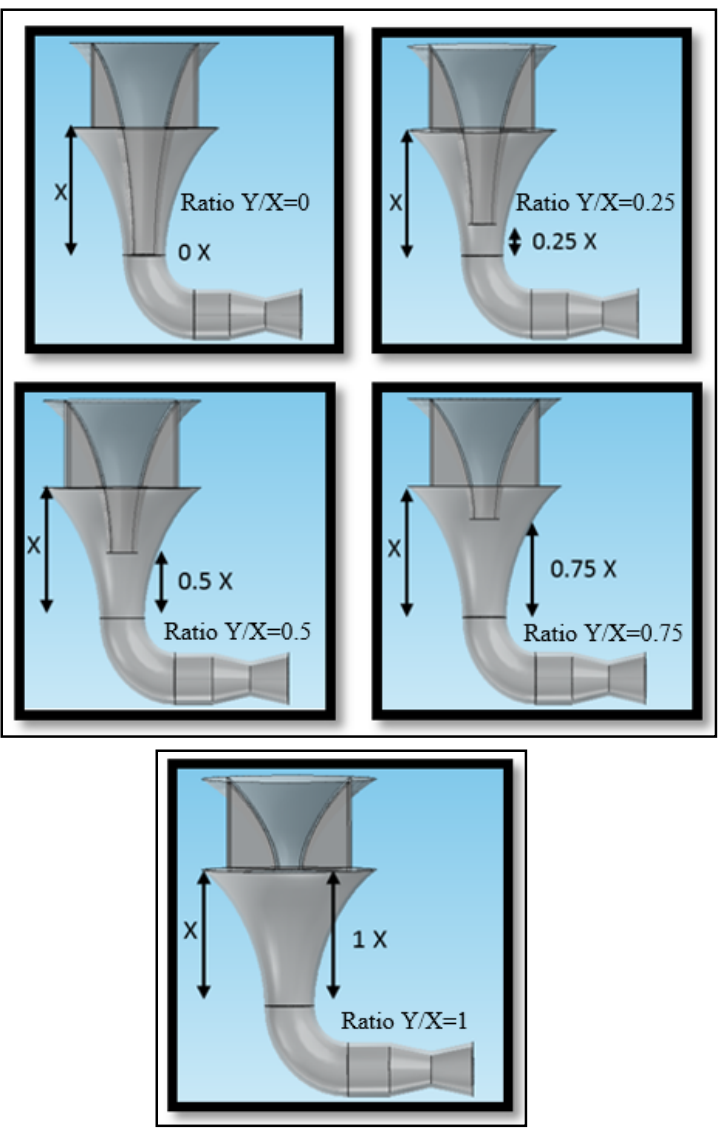

Fig. 13. Ratio of funnel gap variation

\subsubsection{Variation of Rratio Throat's Diameter}

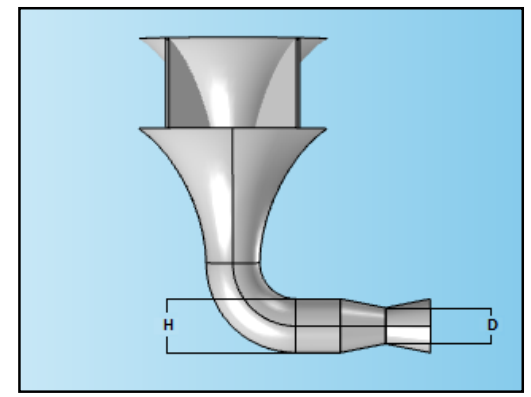

Fig. 14. Ratio of funnel gap variation

There are two variables that will be the reference to the variation of the length of funnel shown in Figure 14, namely:

- $\quad \mathrm{H}=$ Diameter of inlet venturi

- $\quad \mathrm{D}=$ Diameter of throat

$\operatorname{FWS}(\mathrm{m} / \mathrm{s}) \quad=1,2,3,4$
$\mathrm{H}$

D

Ratio

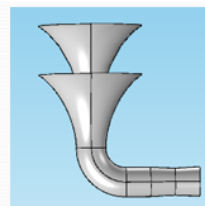

Ratio H/D 1.11

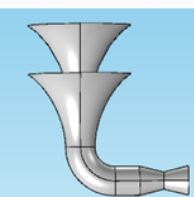

Ratio H/D 2.00
$=10$ feet

$=9$ feet, 8 feet, 7 feet, 6 feet, 5 feet, 4

feet, 3 feet, 2 feet

$=1.11,1.25,1.43,1.67,2.00,2.50$,

$3.33,5.00$
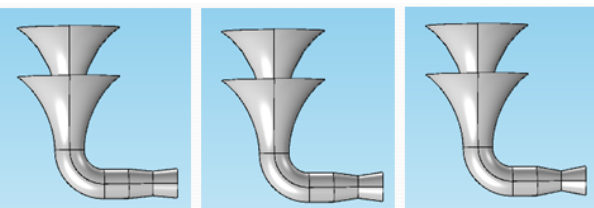

Ratio H/D 1.25

Ratio H/D 1.43

Ratio H/D 1.67 (basis)
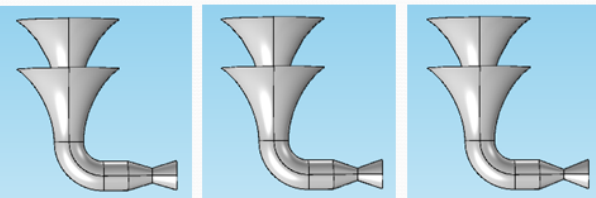

Ratio H/D 2.50 Ratio H/D 3.33 Ratio H/D 5.00 Fig. 15. Ratio of funnel gap variation

\section{Result and Discussion}

\subsection{Result of funnel gap variations}

Distribution of wind speed which discussed are variations in ratio Y/X on Free Wind Stream (FWS) 4 m/s. Variations of FWS $1 \mathrm{~m} / \mathrm{s}-3 \mathrm{~m} / \mathrm{s}$ presented on Table 3 .

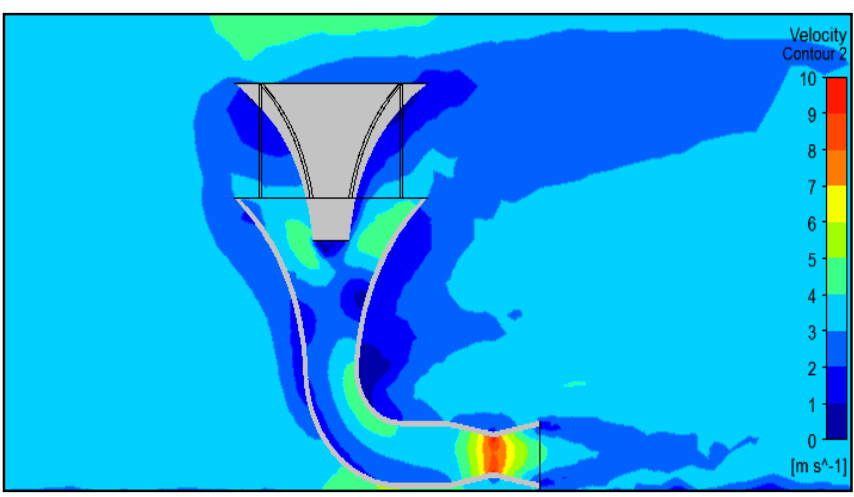

Fig. 16. Velocity distribution on ratio $\mathrm{Y} / \mathrm{X}=1$

From Figure 16, there is variation of the color. Blue color means low speeds and the red color means high

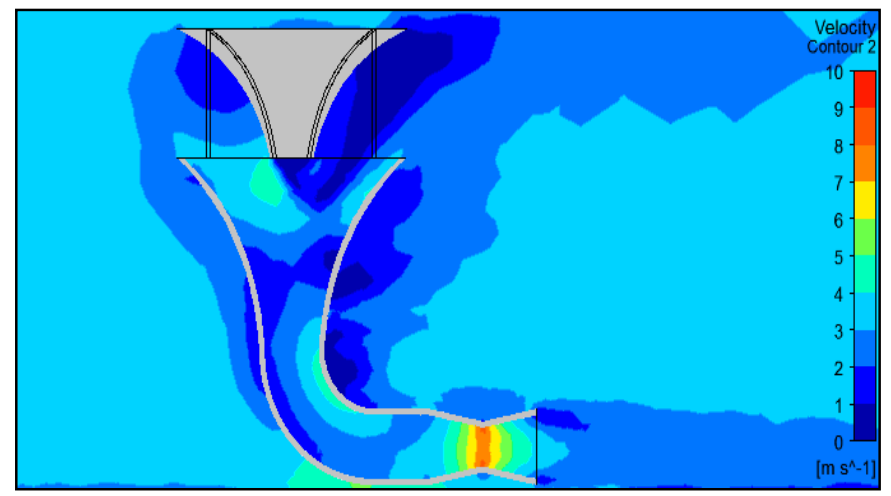

speed. The free wind stream is $4 \mathrm{~m} / \mathrm{s}$ and represented in blue, while the wind speed at the constriction reaches 8.18 $\mathrm{m} / \mathrm{s}$ and is represented in orange. The ratio $\mathrm{Y} / \mathrm{X}=1$ is the ratio between the $\mathrm{Y}$ and $\mathrm{X}$ values in Section II.C.1 where the value $\mathrm{Y}$ is 30 feet, and $\mathrm{X}$ is 30 feet. 
Fig.17. Velocity distribution on ratio $\mathrm{Y} / \mathrm{X}=0.75$

From Figure 17, there is variation of the color. Blue color means low speeds and the red color means high speed. The free wind stream is $4 \mathrm{~m} / \mathrm{s}$ and represented in blue, while the wind speed at the constriction reaches 9.03 $\mathrm{m} / \mathrm{s}$ and is represented in red. The ratio $\mathrm{Y} / \mathrm{X}=0.75$ is the ratio between the $\mathrm{Y}$ and $\mathrm{X}$ values in Section II.C.1 where the value $\mathrm{Y}$ is 22.5 feet, and $\mathrm{X}$ is 30 feet.

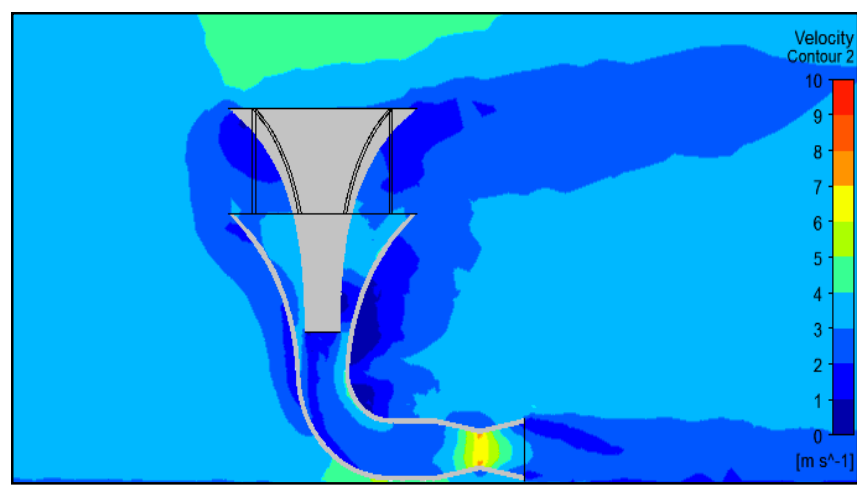

Fig. 18. Velocity distribution on ratio $\mathrm{Y} / \mathrm{X}=0.5$

From Figure 18, there is variation of the color. Blue color means low speeds and the red color means high speed. The free wind stream is $4 \mathrm{~m} / \mathrm{s}$ and represented in blue, while the wind speed at the constriction reaches 7.45 $\mathrm{m} / \mathrm{s}$ and is represented in light orange. The ratio $\mathrm{Y} / \mathrm{X}=0.5$ is the ratio between the $\mathrm{Y}$ and $\mathrm{X}$ values in Section II.C.1 where the value $\mathrm{Y}$ is 15 feet, and $\mathrm{X}$ is 30 feet.

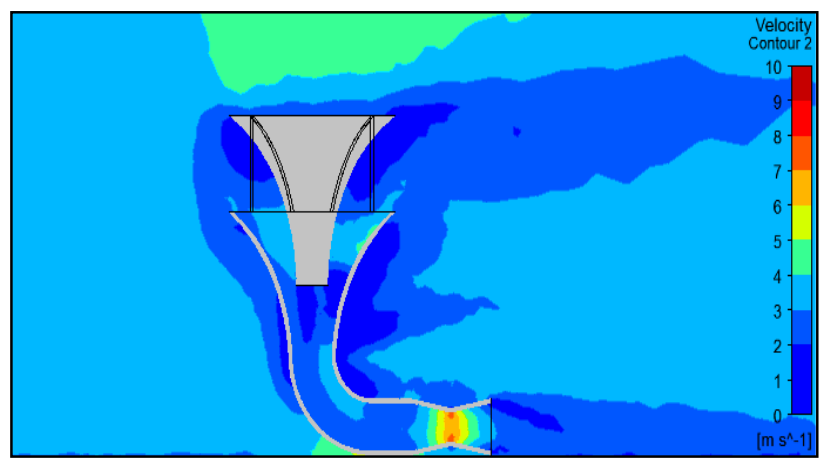

Fig. 19. Velocity distribution on ratio $\mathrm{Y} / \mathrm{X}=0.25$

From Figure 19, there is variation of the color. Blue color means low speeds and the red color means high speed. The free wind stream is $4 \mathrm{~m} / \mathrm{s}$ and represented in blue, while the wind speed at the constriction reaches $7.3 \mathrm{~m} / \mathrm{s}$ and is represented in yellow. The ratio $\mathrm{Y} / \mathrm{X}=0.25$ is the ratio between the $\mathrm{Y}$ and $\mathrm{X}$ values in Section II.C.1 where the value $\mathrm{Y}$ is 7.5 feet, and $\mathrm{X}$ is 30 feet.

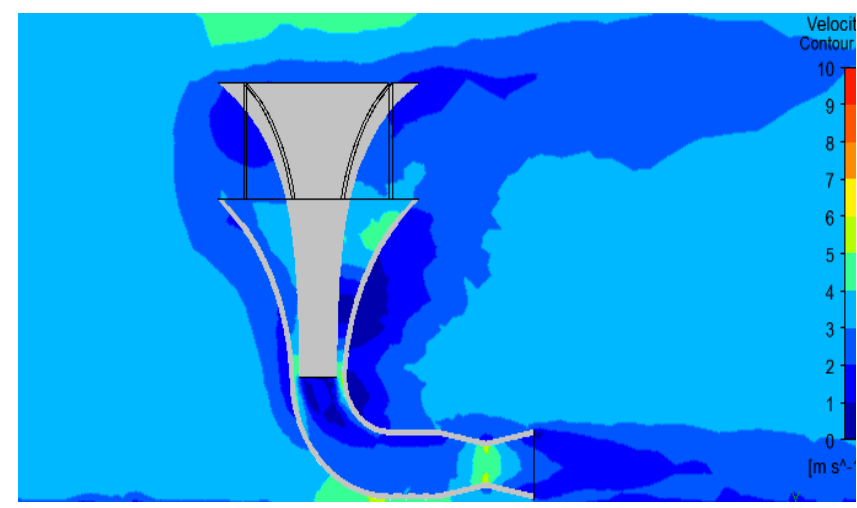

Fig.20. Velocity distribution on ratio $\mathrm{Y} / \mathrm{X}=0$

From Figure 20, there is variation of the color. Blue color means low speeds and the red color means high speed. The free wind stream is $4 \mathrm{~m} / \mathrm{s}$ and represented in blue, while the wind speed at the constriction reaches 5.16 $\mathrm{m} / \mathrm{s}$ and is represented in green. The ratio $\mathrm{Y} / \mathrm{X}=0$ is the ratio between the $\mathrm{Y}$ and $\mathrm{X}$ values in Section II.C.1 where the value $\mathrm{Y}$ is 0 feet, and $\mathrm{X}$ is 30 feet.

This research analyze the average wind speed at the throat. The following describes the average wind speed at each ratio Y / X and Free Wind Stream.

Table 3. Simulation result of each ratio $\mathrm{Y} / \mathrm{X}$ variation and FWS

\begin{tabular}{|l|l|l|l|l|l|}
\hline Simulation Results & 0 & 0.25 & 0.5 & 0.75 & 1 \\
\hline Ratio Y/X & 1.29 & 1.83 & 1.86 & 2.26 & 2.05 \\
\hline FWS $=\mathbf{1 ~ m} / \mathbf{s}$ & 1.29 & 1.83 & 1.86 & 2.26 & 2.05 \\
\hline Wind speed at throat $(\mathrm{m} / \mathrm{s})$ & 2.58 & 3.65 & 3.72 & 4.51 & 4.09 \\
\hline Speed Ratio & 1.29 & 1.83 & 1.86 & 2.26 & 2.05 \\
\hline FWS $=\mathbf{2 ~ m / s ~}$ & 3.87 & 5.47 & 5.58 & 6.77 & 6.14 \\
\hline Wind speed at throat (m/s) & 1.29 & 1.83 & 1.86 & 2.26 & 2.05 \\
\hline Speed Ratio & \multicolumn{7}{|c|}{} \\
\hline FWS $=\mathbf{3} \mathbf{~ m / s ~}$ & 5.16 & 7.3 & 7.45 & 9.03 & 8.18 \\
\hline Wind speed at throat (m/s) & 1.29 & 1.83 & 1.86 & 2.26 & 2.05 \\
\hline Speed Ratio & FWS $=\mathbf{4 ~ m / s ~}$ &
\end{tabular}

Table 3 is the data results of the variations in the ratio $\mathrm{Y} / \mathrm{X}$ as well as free wind stream variation to the speed at the throat obtained using ANSYS 16.2 is shown in a graph such as Figure 21.

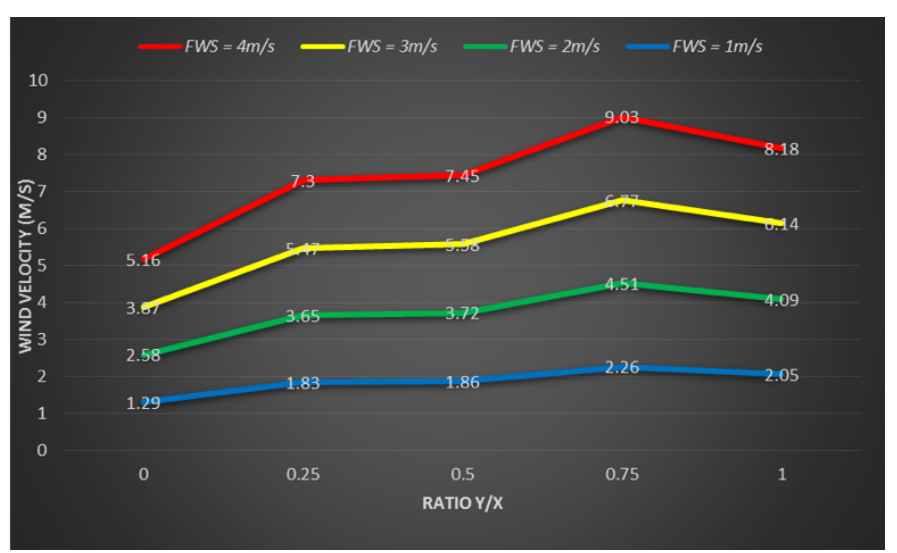

Fig. 21. Graphicof effect of $Y / X$ ratio to wind velocity at venturi

From the research that have been conducted using ANSYS 16.2, it was found that the optimal ratio of funnel gap (Y) and length of the funnel (X) at low wind speed variation is 0.75 . Increase the wind speed reached 2.26 times to the free wind stream with each speed detail in Table 3 .

\subsection{Results of throat diameter variations}

Distribution of wind speed which discussed are variations in ratio H/D on Free Wind Stream (FWS) $4 \mathrm{~m} / \mathrm{s}$. Variations of FWS $1 \mathrm{~m} / \mathrm{s}-3 \mathrm{~m} / \mathrm{s}$ presented on Table 4 . 


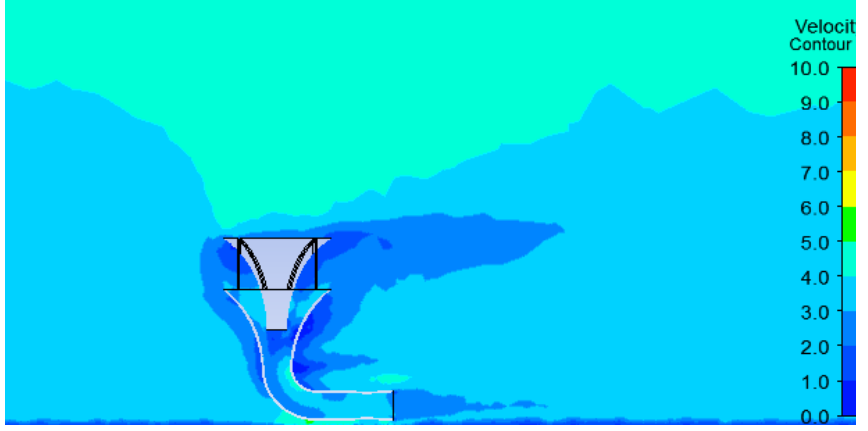

Fig. 22. Velocity distribution on ratio $H / D=1.11$

Figure 22 shows the distribution of wind speeds where blue indicates low speed and red colors indicate high speed. The throat diameter is 9 feet. The average wind speed at the throat is $3.74 \mathrm{~m} / \mathrm{s}$.

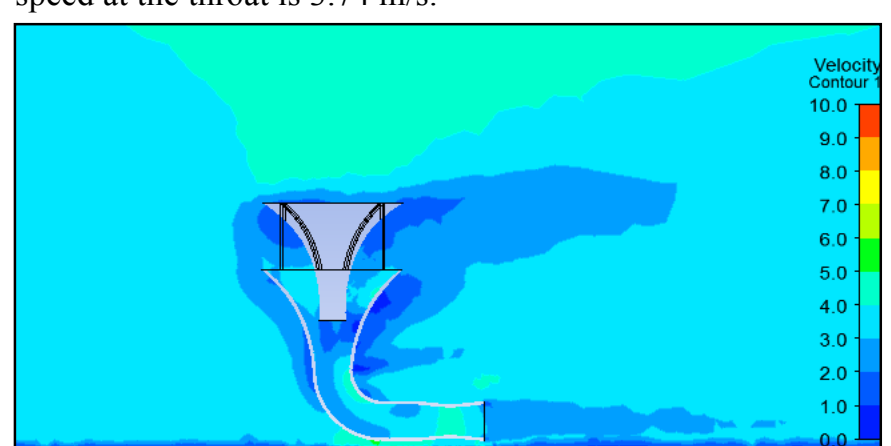

Fig. 23. Velocity distribution on ratio $\mathrm{H} / \mathrm{D}=1.25$

Figure 23 shows the velocity distribution in the throat 8 feet diameter. An increase in the speed of previous variations are marked in light green color. The average wind speed at the throat is $4.80 \mathrm{~m} / \mathrm{s}$.

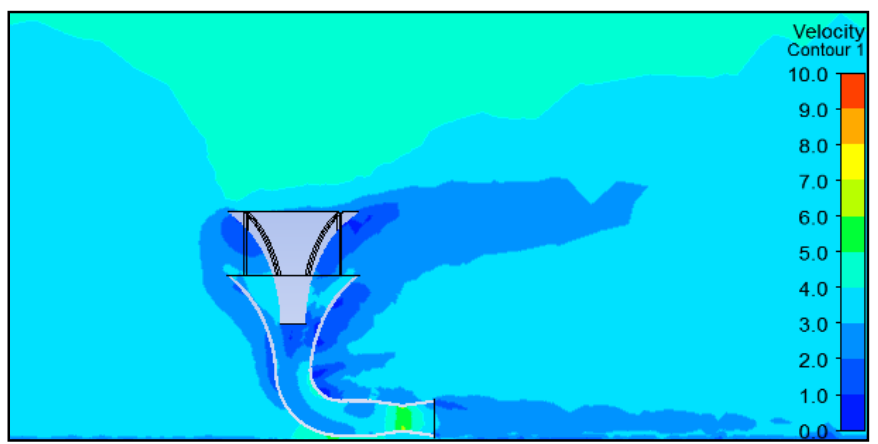

Fig. 24. Velocity distribution on ratio $\mathrm{H} / \mathrm{D}=1.43$

Figure 24 shows the velocity distribution in the throat 7 feet diameter. An increase in the speed of previous variations are marked in green color. The average wind speed at the throat is $6 \mathrm{~m} / \mathrm{s}$.

Fig.25. Velocity distribution on ratio $H / D=1.67$

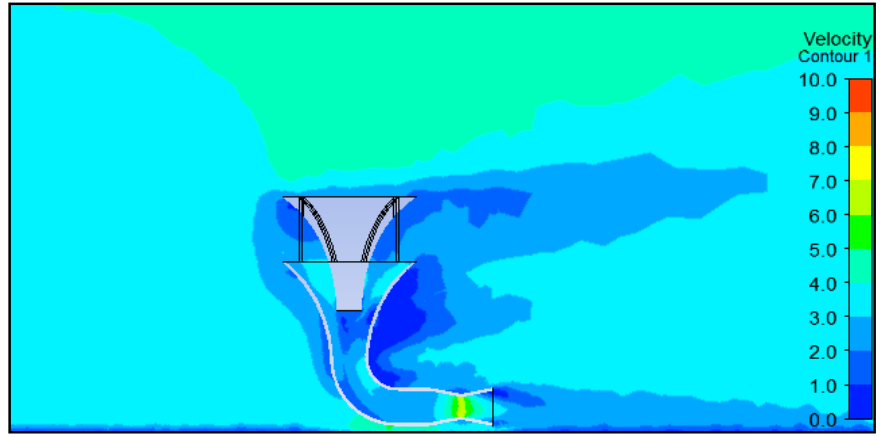

Figure 25 shows the velocity distribution in the throat 6 feet diameter. This ratio is the ratio of the base used for validation. An increase in the speed of the previous variation that is characterized by the color of the throat is more yellow. The average wind speed at the throat is $7.45 \mathrm{~m} / \mathrm{s}$

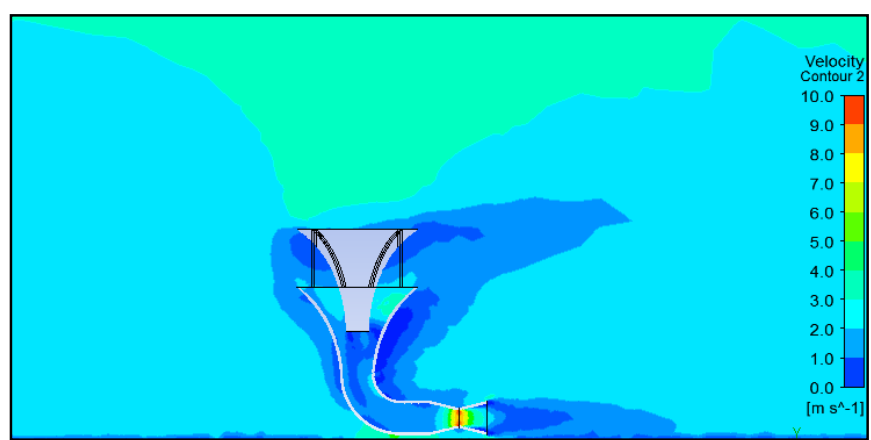

Fig. 26. Velocity distribution on ratio $\mathrm{H} / \mathrm{D}=2.00$

Figure 26 shows the velocity distribution in the throat 5 feet diameter. An increase in the speed of previous variations are marked in red color. The average wind speed at the throat is $9.23 \mathrm{~m} / \mathrm{s}$.

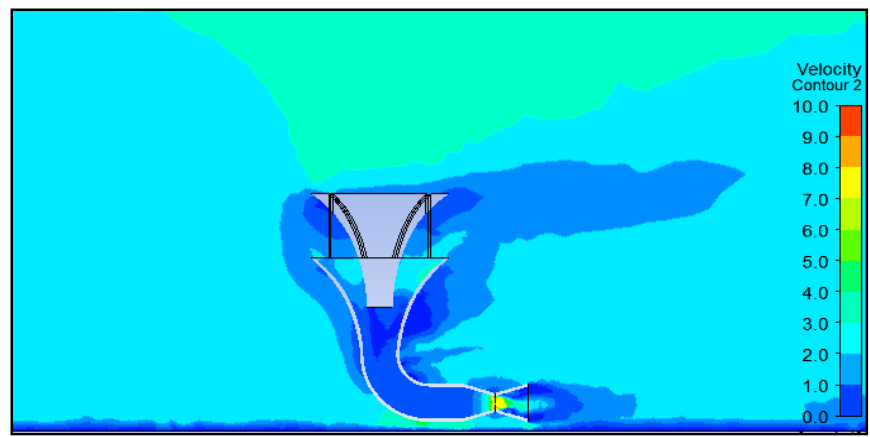

Fig. 27. Velocity distribution on ratio $H / D=2.50$

Figure 27 shows the velocity distribution in the throat 4 feet diameter. There is a speed reduction from the previous variation that is characterized by the color of the throat back in yellow after the red in the previous variations. This shows that the decrease in the value of 
the diameter of the esophagus is not always better at increase wind speed. The average wind speed at the throat is $8.22 \mathrm{~m} / \mathrm{s}$.

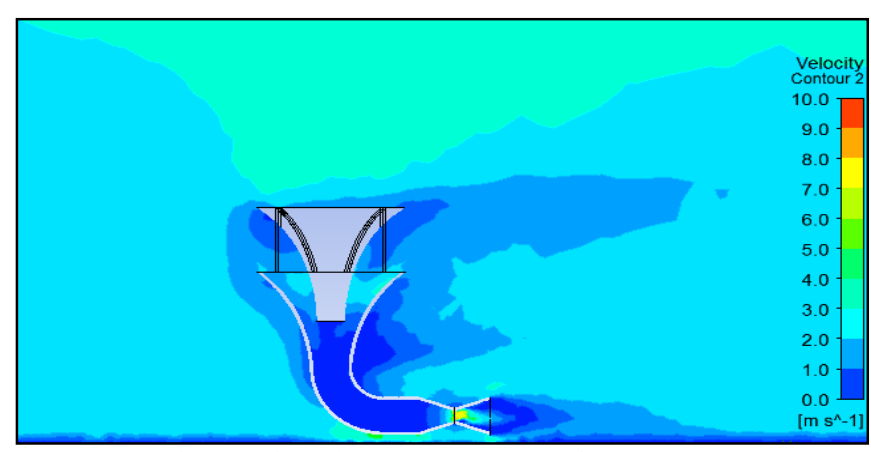

Fig. 28. Velocity distribution on ratio $H / D=3.33$

Figure 28 shows the velocity distribution in the throat 3 feet diameter. A decrease in the speed of previous variations are marked in yellow color. The average wind speed at the throat is $7.44 \mathrm{~m} / \mathrm{s}$.

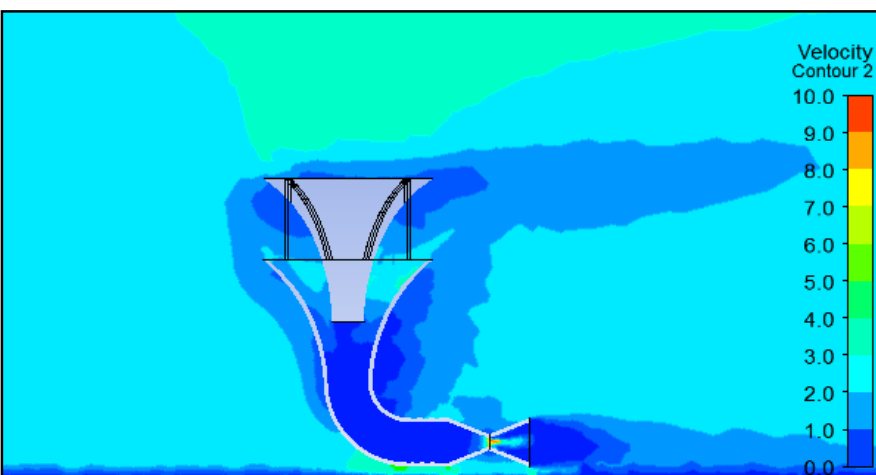

Fig. 29. Velocity distribution on ratio $H / D=3.33$

Figure 28 shows the velocity distribution in the throat 2 feet diameter. A decrease in the speed of previous variations are marked in blue color. The average wind speed at the throat is $2.09 \mathrm{~m} / \mathrm{s}$.

Table 4. Simulation result of each ratio H/Dand FWS

\begin{tabular}{|c|c|}
\hline Simulations using ANSYS & \\
\hline Ratio H/D & \begin{tabular}{|l|l|l|l|l|l|l|l|}
1.11 & 1.25 & 1.43 & 1.67 & 2.00 & 2.50 & 3.33 & 5 \\
\end{tabular} \\
\hline Free Stream Wind $4 \mathrm{~m} / \mathrm{s}$ & \\
\hline wind speed at throat $(\mathrm{m} / \mathrm{s})$ & \begin{tabular}{|l|l|l|l|l|l|l|l|}
3.74 & 4.80 & 6.00 & 7.45 & 9.23 & 8.22 & 7.44 & 2 \\
\end{tabular} \\
\hline wind speed ratio & \begin{tabular}{|c|c|c|c|c|c|c|c|}
0.94 & 1.20 & 1.50 & 1.86 & 2.31 & 2.06 & 1.86 & 0 \\
\end{tabular} \\
\hline Free Stream Wind $3 \mathrm{~m} / \mathrm{s}$ & \\
\hline wind speed at throat $(\mathrm{m} / \mathrm{s})$ & \begin{tabular}{|l|l|l|l|l|l|l|l}
2.82 & 3.48 & 4.50 & 5.58 & 6.94 & 5.76 & 5.58 & 1 \\
\end{tabular} \\
\hline wind speed ratio & \begin{tabular}{|l|l|l|l|l|l|l|l|l|}
0.94 & 1.16 & 1.50 & 1.86 & 2.31 & 1.92 & 1.86 & 0 \\
\end{tabular} \\
\hline Free Stream Wind $2 \mathrm{~m} / \mathrm{s}$ & \\
\hline wind speed at throat $(\mathrm{m} / \mathrm{s})$ & \begin{tabular}{|l|l|l|l|l|l|l|l}
1.86 & 2.40 & 3.01 & 3.72 & 4.60 & 3.78 & 3.71 & 1 \\
\end{tabular} \\
\hline wind speed ratio & \begin{tabular}{|l|l|l|l|l|l|l|l}
0.93 & 1.20 & 1.51 & 1.86 & 2.30 & 1.89 & 1.86 & 0 \\
\end{tabular} \\
\hline Free Stream Wind $1 \mathrm{~m} / \mathrm{s}$ & \\
\hline wind speed at throat $(\mathrm{m} / \mathrm{s})$ & \begin{tabular}{|l|l|l|l|l|l|l|l|}
0.94 & 1.15 & 1.40 & 1.85 & 2.30 & 1.89 & 1.85 & 0 \\
\end{tabular} \\
\hline wind speed ratio & \begin{tabular}{|c|c|c|c|c|c|c|c|}
0.94 & 1.15 & 1.40 & 1.85 & 2.30 & 1.89 & 1.85 & 0 \\
\end{tabular} \\
\hline
\end{tabular}

Table 4 is the data results of the variations in the ratio $\mathrm{H} / \mathrm{D}$ as well as free wind stream variation to the speed at the throat obtained using ANSYS 16.2 is shown in a graph such as Figure 30.

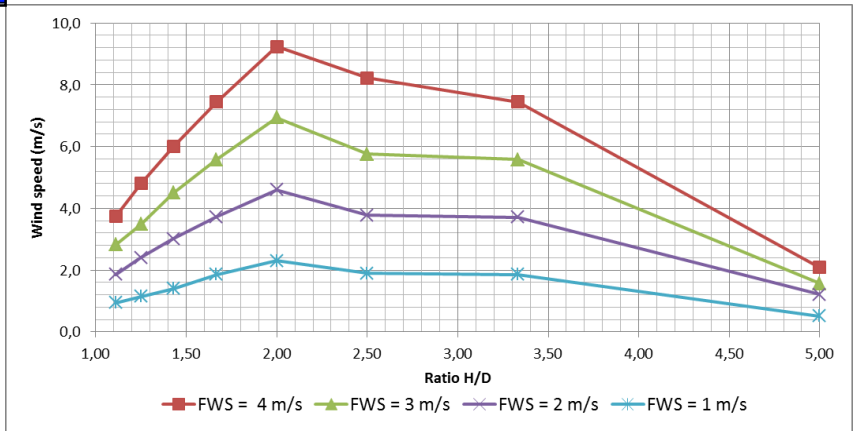

Fig. 30. Graphic of effect of $\mathrm{Y} / \mathrm{X}$ ratio to wind velocity at venturi

From the research that have been conducted using ANSYS 16.2, it was found that optimal ratio of the diameter of inlet venturi $(\mathrm{H})$ and throat diameter $(\mathrm{D})$ at low wind speed variation is 2 . Increase the wind speed reached 2.31 times to the free wind stream with each speed detail in Table 4.

\subsection{Comparing with the Existing Design}

The result on Secntion III.A and III.B will be compared to the existing design on the reference paper [1] and the data obtained as shown in Table 5.

Table 5. Comparison of basic with optimal design 


\begin{tabular}{|c|c|c|}
\hline Design & Wind velocity at venturi & Speed Ratio \\
\hline Basic & $7.45 \mathrm{~m} / \mathrm{s}$ & 1.86 \\
\hline Ratio Y/X optimal & $9.03 \mathrm{~m} / \mathrm{s}$ & 2.26 \\
\hline Ratio H/D optimal & $9.23 \mathrm{~m} / \mathrm{s}$ & 2.31 \\
\hline
\end{tabular}

The existing design INVELOX has increased the wind speed by 1.86 times, while this research increased the wind speed in the optimal ratio $\mathrm{Y} / \mathrm{X}$ and $\mathrm{H} / \mathrm{D}$ by 2.26 times and 2.31 times. Comparing to the reference that the increased of the wind speed in the optimal ratio $\mathrm{Y} / \mathrm{X}$ and $\mathrm{H} / \mathrm{D}$ better $21.5 \%$ and $24.2 \%$ than the existing design.

\section{Conclusion}

The highest wind speeds occur at a ratio $\mathrm{Y} / \mathrm{X} 0.75$ for variation of funnel gap and the ratio H/D 2.00 for the variation of throat diameter. The wind speed reached 2.26 times faster for variation of funnel gap and 2.31 faster for variation of throat diameter. This design is $21.5 \%$ better than the basic design for the variation of funnel gap and $24.2 \%$ better than the basic design for the variation of throat diameter.

\section{References}

1. D. Allaei, Y. Andreopoulos, Energy, 69, 336-344 (2014)

2. D. Allaei, Y. Andreopoulos, "INVELOX: a new concept in wind energy harvesting". In: ASME 2013 7 th international conference on energy sustainability $\& 11$ th fuel cell science, engineering and technology conference ES-fuel cell, Minneapolis, MN, USA. July 14-19, (2013)

3. D. Allaei, Using CFD to predict the performance of innovative wind power generators, Proc. of the 2012 COMSOL Conf., Boston, (2012)

4. L. Chen, F.L. Ponta, L.I. Lago, Energy. Sustain. Dev., 15, 398-410 (2014)

5. N.M. Kumar, M.S.P. Subathra, O.D. Cota, Proc. Tech 21, 33-40 (2015)

6. M. Johanson, Evaluation of RANS turbulence models for the hydrodynamic analysis of an axisymmetric streamlined body with special consideration of the velocity distribution in the stern region, Master Thesis, KTH, School of Eng. Sciences (SCI), Aeronautical and Vehicle Eng., (2012)

7. I.B. Celik, Introductory Turbulence Modeling, Lecture Notes, Mechanical \& Aerospace Engineering Dept., West Virginia University, 26506-6106 (1999)

8. C\&F Green Energy, CF 20 C\&F Green Energy Brochure, http://www.cfgreenenergy.com/cf-20/, April 21, (2016)

9. ANSYS, Inc., ANSYS Workbench User's Guide. November, (2009)

10. ANSYS, Inc., ANSYS Fluent Theory Guide, November, (2013)
11. ANSYS Inc., Introduction to ANSYS Meshing, March (2016)

12. GEF, WhyPGen, BPPT, UNDP, Potential Wind Power Generations in Indonesia, Accessed from http://whypgen-bppt.com/id/, April 21, (2016)

13. ANSYS Inc., Introductory FLUENT Training, December, (2006)

14. A. Bakker, Lecture 7 - Meshing: Applied Computational Fluid Dynamics. Accessed from http://www.bakker.org, June 1, (2016)

15. H.K. Versteeg, W. Malalasekera, An Introduction to Computational Fluid Dynamics the Finite Volume Method, Longman Scientific \& Technical, Inc., New York, (199 